\title{
ELECTROCARDIOGRAMS OF RIGHT VENTRICULAR HYPERTROPHY IN BILHARZIAL COR PULMONALE
}

\author{
BY \\ H. BADAWI AND A. M. NOMEIR \\ From the Cardiovascular Centre, Department of Medicine, Faculty of Medicine, University of Alexandria, U.A.R. \\ Received June 16, 1964
}

The clinical manifestations and differential diagnosis of bilharzial cor pulmonale are well established (Bedford, Aidaros, and Girgis, 1946; El Ramly et al., 1953; Salah, 1958, Badawi et al., 1961). It is usually possible to differentiate between early and advanced cases, but more refined grading is not easy to achieve at the bedside. Our attempts to grade the clinical signs of right ventricular hypertrophy or the auscultatory signs in the pulmonary area proved unsuccessful and failed to predict the height of the pulmonary artery pressure. Radiological examination is not helpful in detecting mild right ventricular enlargement or in assessing the degree of right ventricular hypertrophy. The size of the pulmonary artery is not related to the degree of pulmonary hypertension (Salah, 1958; Badawi et al., 1961). Application of the knowledge gained from pulmonary arteriography in the interpretation of the plain radiograph (Salah et al., 1963) has helped in judging the degree of underlying arterial changes. The signs in the plain radiograph, however, are not sufficient for accurate assessment.

It seemed that electrocardiography might prove helpful in assessing the severity of the disease. Cosby et al. (1952, 1953), Walker, Helm, and Scott (1955), Walker, Scott, and Helm (1955), and Goodwin and Abdin (1959) found a correlation between electrocardiographic changes and the degree of pulmonary hypertension as well as the size of the right ventricle at necropsy, in congenital and acquired cor pulmonale. The cardiographic changes were affected not only by the degree of pulmonary hypertension but also by the nature of the disease studied, and as a whole the changes were more pronounced in the congenital group (Goodwin and Abdin, 1959). El Sherif (1953) correlated the electrocardiographic findings with the hæmodynamic data in 16 patients with bilharzial cor pulmonale; he thought that right ventricular hypertrophy was preceded by a stage of right ventricular dilatation which produced slurring or notching of the right præcordial complexes. These changes disappeared when right ventricular hypertrophy was established, and the electrocardiogram showed a pattern of pure right ventricular hypertrophy. Naïm (1955) reported on the vectorcardiogram in bilharzial cor pulmonale and stressed that the pattern was consistent with a "systolic overload" and that bundle-branch block was absent. Of 26 patients studied by Foda (1959), 7 had incomplete, and 1 had complete, right bundle-branch block. He considered that the pattern of incomplete right bundle-branch block occurred with high systolic load when the total pulmonary resistance was more than $9 \cdot 5$ units.

This paper reports the electrocardiographic findings and their relation to the hæmodynamic data in bilharzial cor pulmonale.

\section{SubJeCtS AND MethodS}

Twenty patients with proved bilharzial cor pulmonale uncomplicated by other cardiovascular diseases or anæmia were studied. Besides careful clinical examination, routine investigations, and radiological 
studies, the electrocardiographic examination included the 12 conventional leads with the addition in some cases of leads V3R and V7. All the subjects were studied by right heart catheterization with measurement of pressures, cardiac output, and pulmonary resistance. The diagnosis of "early cases" with normal resting pulmonary pressure was confirmed by the occurrence of pulmonary hypertension after exercise and the demonstration of the characteristic bilharzial pattern by the pre-wedged pulmonary angiogram (Salah et al., 1963).

The electrocardiograms were analysed with regard to the electrical axis in the frontal plane, clockwise rotation, $P$ wave in the lead showing maximal changes, $P-R$ interval, the $Q R S$ in aVR, V3R when recorded, and V1 and V5. The height of $R$ and depth of $S$ waves as well as the $R / S$ ratios were measured in the right and left præcordial leads, the time of onset of the intrinsicoid deflection was noted as well as the pattern of the QRS complex and S-T shifts and T wave inversion.

Cardiographic changes of right ventricular hypertrophy were graded as follows.

Grade O: None of the electrocardiographic criteria of right ventricular hypertrophy as defined by Myers, Klein, and Stofer (1948), Sokolow and Lyon (1949), Lipman and Massie (1959), and Wasserburger and Brown (1958).

Grade I: presence of QRS changes indicative of right ventricular hypertrophy in one lead only.

Grade II: presence of QRS changes indicative of right ventricular hypertrophy in any two leads.

Grade III: $\mathbf{R} / \mathrm{S}$ ratio more than unity in all the right præcordial leads and an $\mathrm{R} / \mathrm{S}$ ratio less than unity in $\mathrm{V} 5$ or depression of $\mathrm{S}-\mathrm{T}$ with inversion of $\mathrm{T}$ in $\mathrm{V} 1$.

Grade IV: $\mathrm{R} / \mathrm{S}$ ratio more than unity in all the right leads and less than unity in V5 as well as S-T depression over the right leads or delayed intrinsicoid deflection over the right or $\mathrm{qR}$ over the right. It should be mentioned that isolated $T$ wave inversion in the præcordial leads was not taken into consideration when grading the degree of right ventricular hypertrophy. Though these $\mathrm{T}$ wave abnormalities were striking yet there was marked dissociation between them and the changes in QRS complexes indicative of right ventricular hypertrophy.

Each electrocardiographic change was correlated with the right ventricular systolic pressure, the pulmonary artery systolic pressure, the mean pulmonary artery pressure, and the pulmonary vascular resistance.

\section{RESULTS}

Table I summarizes the hæmodynamic and electrocardiographic data.

Electrocardiographic Analysis. (a) Axis in the frontal plane. 9 patients showed right axis deviation of more than $+110^{\circ}$ ranging from $+113^{\circ}$ to $+176^{\circ}$ : they included patients with all grades of pulmonary hypertension and pulmonary vascular resistance. Of the remaining 11,3 had axes of $+90,+92$, and +105 , respectively, and 8 had normal axes ranging from $-7^{\circ}$ to $+85^{\circ}$. All the 4 patients with normal resting pulmonary pressure had normal axes.

Clockwise rotation was diagnosed when the S wave extended to V6 and was at least $7 \mathrm{~mm}$. in V5. When these changes were associated with a QR pattern in VR the clockwise rotation was considered marked. Clockwise rotation occurred in 16 patients: in the remaining 4 there was no clockwise rotation, and the pulmonary pressure and vascular resistance were normal at rest in 3 while the pressure was mildly raised in the fourth without an increase in the resting pulmonary vascular resistance. Only 1 of the 4 with a normal resting pulmonary pressure and resistance had mild clockwise rotation.

The $P$ wave was within normal limits in 16: in one of them it was $2.5 \mathrm{~mm}$. high and $0.1 \mathrm{sec}$. in duration; in 5 it was peaked in shape but normal in dimensions. Of the remaining 4,3 had peaked $P$ waves more than $2.5 \mathrm{~mm}$. in height and in the fourth the duration of the $P$ wave was $0.12 \mathrm{sec}$. and its. height was normal. None of the patients had increases in jugular venous pressure, right atrial pressure, or diastolic ventricular pressure, and though peaking of the $P$ wave or $P$ pulmonale was always associated with a right ventricular systolic pressure above $50 \mathrm{~mm}$. $\mathrm{Hg}, 6$ patients had ventricular systolic pressures over $50 \mathrm{~mm}$. $\mathrm{Hg}$ with a normal $\mathrm{P}$ wave.

A prolonged P-R interval occurred in only one patient and it was $0.2 \mathrm{sec}$. in 2 others.

The $R$ wave in $V R$ was $5 \mathrm{~mm}$. or more in 5 patients: their pulmonary vascular resistance was more than 6 units, and all except one had a pulmonary systolic pressure over 60 and a mean pressure over 
TABLE I

Hemodynamic and EleCtrocardiographic Data

\begin{tabular}{|c|c|c|c|c|c|c|c|c|c|c|c|c|c|c|c|c|c|}
\hline \multirow[t]{3}{*}{ No. } & \multirow{2}{*}{\multicolumn{3}{|c|}{$\begin{array}{c}\text { Resting PA } \\
\text { pressure } \\
(\mathrm{mm} . \mathrm{Hg})\end{array}$}} & \multirow{3}{*}{$\underset{\text { (1./min.) }}{\mathrm{CO}}$} & \multirow{3}{*}{$\underset{\text { (units) }}{\text { PVR }}$} & \multirow[t]{3}{*}{ PI } & \multirow[t]{3}{*}{ Axis } & \multicolumn{2}{|c|}{ aVR } & \multicolumn{2}{|c|}{ V1 } & \multirow{3}{*}{$\begin{array}{l}\text { VAT } \\
\text { (sec.) }\end{array}$} & \multirow{3}{*}{$\frac{\text { V5 }}{\text { ratio }}$} & \multirow{3}{*}{$\begin{array}{c}\text { Voltage } \\
\text { of } \\
\text { RV1+ } \\
\text { SV5 } \\
\text { (mm.) }\end{array}$} & \multirow{3}{*}{$\begin{array}{l}\text { Grade } \\
\text { of } \\
\text { RVH }\end{array}$} & \multirow{3}{*}{$\begin{array}{c}\text { S-T } \\
\text { depres- } \\
\text { sion }\end{array}$} & \multirow{3}{*}{$\begin{array}{c}\text { T wave } \\
\text { inver- } \\
\text { sion }\end{array}$} \\
\hline & & & & & & & & \multirow{2}{*}{$\begin{array}{c}\text { Height } \\
\text { of R } \\
(\mathrm{mm} .)\end{array}$} & \multirow{2}{*}{$\begin{array}{l}\mathbf{Q} / \mathbf{R} \\
\text { ratio }\end{array}$} & \multirow{2}{*}{$\begin{array}{c}\text { Height } \\
\text { of R } \\
\text { (mm.) }\end{array}$} & \multirow{2}{*}{$\underset{\text { ratio }}{\mathbf{R} / \mathbf{S}}$} & & & & & & \\
\hline & $\mathbf{S}$ & D & $\mathbf{M}$ & & & & & & & & & & & & & & \\
\hline $\begin{array}{l}1 \\
2 \\
3 \\
4 \\
5 \\
6\end{array}$ & $\begin{array}{l}80 \\
64 \\
62 \\
25 \\
17 \\
50\end{array}$ & $\begin{array}{r}40 \\
44 \\
31 \\
13 \\
5 \\
16\end{array}$ & $\begin{array}{l}66 \\
50 \\
42 \\
18 \\
12 \\
30\end{array}$ & $\begin{array}{l}8 \\
6 \cdot 6 \\
5 \cdot 4 \\
7 \\
6 \cdot 8 \\
-\end{array}$ & $\begin{array}{l}7 \\
6 \\
6 \cdot 4 \\
1 \cdot 5 \\
1 \cdot 3 \\
-\end{array}$ & $\begin{array}{l}\bar{z} \\
\bar{z} \\
\bar{z}\end{array}$ & $\begin{array}{l}+114 \\
+85 \\
+168 \\
+15 \\
+15 \\
+10\end{array}$ & $\begin{array}{l}5 \\
2 \\
3 \cdot 5 \\
0 \\
0 \\
3\end{array}$ & $\begin{array}{c}0 \cdot 6 \\
2 \cdot 7 \\
0 \cdot 57 \\
\infty \\
\infty \\
1 \cdot 3\end{array}$ & $\begin{array}{c}12 \\
4 \\
12 \cdot 5 \\
1 \cdot 5 \\
6 \\
3\end{array}$ & $\begin{array}{l}6 \\
1 \\
3 \cdot 6 \\
0 \cdot 27 \\
0.46 \\
1\end{array}$ & $\begin{array}{c}0.04 \\
N \\
0.04 \\
N \\
N \\
N\end{array}$ & $\begin{array}{l}0.75 \\
2.5 \\
1.4 \\
\infty \\
3.6 \\
1.2\end{array}$ & $\begin{array}{l}24 \\
11 \cdot 5 \\
23 \\
1 \cdot 5 \\
13 \\
10\end{array}$ & $\begin{array}{l}\text { IV } \\
\text { II } \\
\text { IV } \\
0 \\
0 \\
0\end{array}$ & $\begin{array}{c}\text { V1-V3 } \\
\text { V1-V3 } \\
\text { V1-V5 } \\
= \\
=\end{array}$ & $\begin{array}{l}\mathrm{V} 1-\mathrm{V} 4 \\
\mathrm{~V} 1-\mathrm{V} 4 \\
\mathrm{~V} 1-\mathrm{V} 6 \\
\mathrm{~V} 1-\mathrm{V} 3 \\
\mathrm{~V} 1 \\
\mathrm{~V} 1 \text { and }\end{array}$ \\
\hline 7 & 50 & 30 & 36 & - & - & - & +10 & 2 & 5.5 & 3 & 0.39 & $\mathbf{N}$ & $3 \cdot 3$ & 9 & 0 & V1 & V2 1 and \\
\hline $\begin{array}{r}8 \\
9 \\
10\end{array}$ & $\begin{array}{l}15 \\
52 \\
60\end{array}$ & $\begin{array}{r}3 \\
23 \\
25\end{array}$ & $\begin{array}{r}7 \\
30 \\
35\end{array}$ & $\begin{array}{c}11 \cdot 4 \\
10 \cdot 5 \\
3\end{array}$ & $\begin{array}{l}0.56 \\
2 \cdot 8 \\
6 \cdot 5\end{array}$ & $\bar{z}$ & $\begin{array}{l}+18 \\
+125 \\
+125\end{array}$ & $\begin{array}{l}2 \\
2 \\
6\end{array}$ & $\begin{array}{l}4 \\
1 \cdot 5 \\
0 \cdot 58\end{array}$ & $\begin{array}{l}5 \\
3 \cdot 5 \\
5\end{array}$ & $\begin{array}{l}1 \cdot 25 \\
1.5 \\
10\end{array}$ & $\underset{0.04}{N}$ & $\begin{array}{l}1 \cdot 4 \\
2 \cdot 6 \\
1\end{array}$ & $\begin{array}{r}7 \\
11 \\
33\end{array}$ & $\begin{array}{l}\text { I } \\
\text { I } \\
\text { IV }\end{array}$ & $\overline{\mathrm{v} 1}$ & V1 and \\
\hline $\begin{array}{l}11 \\
12 \\
13 \\
14 \\
15 \\
16 \\
17 \\
18\end{array}$ & $\begin{array}{r}100 \\
53 \\
52 \\
42 \\
84 \\
90 \\
90 \\
157\end{array}$ & $\begin{array}{l}37 \\
33 \\
21 \\
15 \\
25 \\
43 \\
34 \\
46\end{array}$ & $\begin{array}{l}67 \\
41 \\
32 \\
26 \\
47 \\
58 \\
56 \\
87\end{array}$ & $\begin{array}{c}5 \cdot 3 \\
5 \cdot 4 \\
-11 \\
3 \cdot 6 \\
5 \cdot 5 \\
4 \cdot 8 \\
5 \cdot 2\end{array}$ & $\begin{array}{r}11 \cdot 7 \\
7 \cdot 1 \\
1 \cdot 8 \\
10 \cdot 7 \\
8 \cdot 3 \\
11 \\
13.5\end{array}$ & $\begin{array}{l}\overline{-} \\
\overline{-} \\
+ \\
+ \\
\pm\end{array}$ & $\begin{array}{l}+105 \\
+176 \\
+120 \\
-7 \\
+92 \\
+113 \\
+114 \\
+118\end{array}$ & $\begin{array}{l}4 \cdot 5 \\
2 \\
5 \\
1 \\
0 \cdot 5 \\
3 \cdot 5 \\
5 \\
6\end{array}$ & $\begin{array}{l}1 \\
0.75 \\
1 \\
4 \cdot 5 \\
9 \\
1 \\
0 \cdot 5 \\
0.3\end{array}$ & $\begin{array}{r}16 \\
7 \\
8 \\
1 \\
11 \\
99 \\
15 \\
12\end{array}$ & $\begin{array}{l}1.9 \\
1 \\
1.1 \\
0.25 \\
4.4 \\
4.5 \\
3.7 \\
\infty\end{array}$ & $\begin{array}{c}N \\
N \\
N \\
N \\
0.05 \\
0.045 \\
0.04 \\
N\end{array}$ & $\begin{array}{l}1 \\
1 \\
2 \cdot 5 \\
\infty \\
1.9 \\
0 \cdot 85 \\
1 \cdot 1 \\
1\end{array}$ & $\begin{array}{l}26 \\
21 \\
16 \\
1 \\
20 \\
20 \\
30 \\
13\end{array}$ & $\begin{array}{l}\text { IV } \\
\text { III } \\
\text { II } \\
\text { 0 } \\
\text { IV* } \\
\text { IV* } \\
\text { IV* } \\
\text { IV }\end{array}$ & $\begin{array}{c}\mathrm{V} 1-\mathrm{V} 3 \\
\mathrm{~V} 1-\mathrm{V} 3 \\
\overline{-} \\
\mathrm{V} 1-\mathrm{V} 4 \\
\mathrm{~V} 1-\mathrm{V} 4 \\
\mathrm{~V} 1-\mathrm{V} 3 \\
\mathrm{~V} 1-\mathrm{V} 5\end{array}$ & $\begin{array}{l}\mathrm{V} 2 \\
\mathrm{~V} 1-\mathrm{V} 6 \\
\mathrm{~V} 1-\mathrm{V} 4 \\
\mathrm{~V} 1-\mathrm{V} 3 \\
\mathrm{~V} 1-\mathrm{V} 4 \\
\mathrm{~V} 1-\mathrm{V} 6 \\
\mathrm{~V} 1-\mathrm{V} 4 \\
\mathrm{~V} 1-\mathrm{V} 5\end{array}$ \\
\hline 19 & 23 & 6 & 13 & $9 \cdot 4$ & 1.07 & - & +2 & 0.5 & $\mathrm{R} / \mathrm{S} 16$ & 2 & $0 \cdot 2$ & $\mathbf{N}$ & 6 & 4 & 0 & - & $\mathrm{V} 1$ and \\
\hline 20 & 97 & 45 & 66 & 7 & $8 \cdot 3$ & - & +90 & 3 & 1.7 & 7 & 1 & $\mathbf{N}$ & $2 \cdot 2$ & 17 & II & - & \\
\hline
\end{tabular}

$\mathrm{PA}=$ pulmonary artery $(\mathrm{S}=$ systolic, $\mathrm{D}=$ Diastolic, $\mathrm{M}=$ mean $) ; \mathrm{PVR}=$ pulmonary vascular resistance; Axis = Axis in the frontal plane; $\mathrm{RVH}=$ right ventricular hypertrophy; $\mathrm{CO}=$ cardiac output (litres per minute); $\mathrm{PI}=$ =pulmonary incompetence; $\mathrm{VAT}=$ ventricular activation time; $\mathrm{N}=$ normal.

* Right bundle-branch block pattern.

$35 \mathrm{~mm} . \mathrm{Hg}$; yet the relation between the height of the $\mathrm{R}$ wave in this lead and the hæmodynamic data was not linear (Table II).

$Q / R$ ratio in $V R$ was less than unity in 6 patients, unity in 3, and above unity in 10 . The remaining patient had a normal resting pulmonary artery pressure and had no $Q$ wave in aVR which showed an $R / S$ ratio of 16 . The other 3 with normal resting pulmonary artery pressures had a $Q / R$ ratio above unity. As seen from Table II, the relation between this ratio and pulmonary artery pressure and the pulmonary vascular resistance showed a considerable overlap.

The $R$ wave in $V 1$ was $7 \mathrm{~mm}$. or more in 10, whose systolic pulmonary arterial pressures ranged from 52 to $157 \mathrm{~mm}$. $\mathrm{Hg}$ and pulmonary vascular resistances from 6.4 to 13.5 units. On the other hand, an R wave of less than $7 \mathrm{~mm}$. occurred in 10 patients with systolic pressures up to $64 \mathrm{~mm} . \mathrm{Hg}$, and a mean pressure up to $50 \mathrm{~mm}$. $\mathrm{Hg} ; 3$ of them had a raised pulmonary vascular resistance. All

TABLE II

Relation between Height of R, Q/R Ratio in aVR, and Systolic Pulmonary Artery Pressure and Pulmonary VASCULAR 'RESISTANCE (AVERAGE IN BRACKETS)

\begin{tabular}{|c|c|c|c|c|c|c|c|}
\hline & & \multicolumn{3}{|c|}{ Height of $\mathbf{R}(\mathrm{mm})}$. & \multicolumn{3}{|c|}{$\mathrm{Q} / \mathbf{R}$ ratio } \\
\hline & & $0-1 \cdot 9$ & $2-3 \cdot 9$ & $4-6$ & $\begin{array}{c}\text { Above } \\
\text { unity }\end{array}$ & Unity & $\begin{array}{l}\text { Below } \\
\text { unity }\end{array}$ \\
\hline $\begin{array}{l}\text { Systolic pulmonary artery } \\
\text { pressure }(\mathrm{mm} . \mathrm{Hg})\end{array}$ & .. & $\begin{array}{c}17-85 \\
(34)\end{array}$ & $\begin{array}{c}15-97 \\
(59)\end{array}$ & $\begin{array}{c}53-157 \\
(90)\end{array}$ & $\begin{array}{l}15-97 \\
(49.6)\end{array}$ & $\begin{array}{c}52-100 \\
(80 \cdot 7)\end{array}$ & $\begin{array}{c}53-157 \\
(83 \cdot 7)\end{array}$ \\
\hline $\begin{array}{l}\text { Pulmonary vascular } \\
\text { resistance (units) }\end{array}$ & .. & $\begin{array}{c}1 \cdot 07-10 \cdot 7 \\
(3 \cdot 27)\end{array}$ & $\begin{array}{c}0.56-8 \cdot 3 \\
(5 \cdot 62)\end{array}$ & $\begin{array}{c}6.4-13 \cdot 5 \\
(10 \cdot 8)\end{array}$ & $\begin{array}{c}0 \cdot 56-10 \cdot 7 \\
(4 \cdot 1)\end{array}$ & $\begin{array}{c}8 \cdot 3-11 \cdot 7 \\
(10)\end{array}$ & $\begin{array}{c}6 \cdot 4-13 \cdot 5 \\
(8 \cdot 6)\end{array}$ \\
\hline
\end{tabular}

A $Q$ wave was absent in one patient in whom the $R / S$ ratio was 16. 
TABLE III

Relation between Height of R, R/S Ratio in V1 and Systolic Pulmonary Artery Pressure and Pulmonary VASCULAR RESISTANCE (AVERAGE IN BRACKETS)

\begin{tabular}{|c|c|c|c|c|c|c|c|}
\hline & \multicolumn{4}{|c|}{ Height of R (mm.) } & \multicolumn{3}{|c|}{$\mathrm{R} / \mathrm{S}$ ratio } \\
\hline & $1-3 \cdot 9$ & $4-7 \cdot 9$ & $8-11 \cdot 9$ & $12-16$ & $\begin{array}{l}\text { Below } \\
\text { unity }\end{array}$ & Unity & $\begin{array}{l}\text { Above } \\
\text { unity }\end{array}$ \\
\hline $\begin{array}{l}\text { Systolic pulmonary pressure } \\
\text { (mm. Hg) }\end{array}$ & $\begin{array}{l}23-52 \\
(38 \cdot 4)\end{array}$ & $\begin{array}{c}15-100 \\
(45)\end{array}$ & $\begin{array}{c}52-90 \\
(75)\end{array}$ & $\begin{array}{c}62-157 \\
(97 \cdot 8)\end{array}$ & $\begin{array}{l}17-50 \\
(31 \cdot 4)\end{array}$ & $\begin{array}{c}50-97 \\
(66)\end{array}$ & $\begin{array}{c}15-157 \\
(76.5)\end{array}$ \\
\hline $\begin{array}{cccc}\text { Pulmonary vascular resistance } \\
\text { (units) } & . & . & \cdots\end{array}$ & $\begin{array}{c}1 \cdot 5-2 \cdot 8 \\
(1 \cdot 8)\end{array}$ & $\begin{array}{c}0.56-11 \cdot 7 \\
(5.9)\end{array}$ & $\begin{array}{c}8 \cdot 3-10 \cdot 7 \\
(9 \cdot 5)\end{array}$ & $\begin{array}{c}6.4-13 \cdot 5 \\
(9 \cdot 9)\end{array}$ & $\begin{array}{c}1 \cdot 07-1 \cdot 8 \\
(1 \cdot 4)\end{array}$ & $\begin{array}{l}6-8 \cdot 3 \\
(7 \cdot 1)\end{array}$ & $\begin{array}{c}0 \cdot 56-13 \cdot 5 \\
(7 \cdot 8)\end{array}$ \\
\hline
\end{tabular}

the 4 patients with resting normal pulmonary pressures had an $R$ less than $7 \mathrm{~mm}$. As seen from Table III, the relation between the height of $\mathrm{R}$ in V1 and the pulmonary systolic pressure and vascular resistance showed an appreciable overlap.

$R / S$ ratio in $V l$ was less than one in only 5 patients, 3 of whom had normal resting pulmonary artery pressures and 2 of whom had mild pulmonary hypertension; their pulmonary vascular resistances were normal. It is worth noting that in the other patient with a normal resting pulmonary artery pressure, an R/S ratio of 1.25 in V1 was the sole abnormality in his electrocardiogram. In the remaining 15 the $\mathrm{R} / \mathrm{S}$ ratio was unity or more, but its correlation with the systolic pulmonary vascular resistance showed a wide scatter.

No additional information was gained from the tracings which included lead V3R.

The $S$ wave in $V 5$ was $7 \mathrm{~mm}$. or more in 16 patients who all, except one, had resting pulmonary hypertension. Its magnitude could not be related to the degree of pulmonary hypertension. The $S$ wave was absent in 2 patients and was less than $4 \mathrm{~mm}$. in 2.

Changes in the $R / S$ ratio in $V 5$ were much less impressive than in right præcordial leads: 14 patients had a ratio of more than one and the $R$ and $S$ waves were equal in 4 ; the ratio was less than one in only 2.

$R$ in $V 1$ plus $S$ in $V 5$ measured $10.5 \mathrm{~mm}$. or more in 14 patients whose pulmonary arterial systolic pressures ranged from 17 to $157 \mathrm{~mm}$. $\mathrm{Hg}$. The remaining 6 patients included 3 who had normal resting pulmonary pressures and 3 who had mild pulmonary hypertension with systolic pressures up to $50 \mathrm{~mm}$. $\mathrm{Hg}$ and a mean pressure up to $36 \mathrm{~mm}$. $\mathrm{Hg}$.

The $Q R S$ in the right præcordial leads was either normal (rS), or the $\mathrm{R}$ wave was dominant, an RS, Rs, qRs, qR, or rsR' pattern being seen. A qR pattern occurred in only one patient with grade 4 electrocardiographic changes who had the highest pulmonary artery pressure in this series $(157 / 46$ with a mean of $87 \mathrm{~mm}$. $\mathrm{Hg}$ ). A qRs pattern was found in 3 other patients, all of whom had also grade 4 electrocardiographic right ventricular hypertrophy.

Apart from the 3 patients showing right bundle-branch block pattern the intrinsicoid deflection was delayed to $0.04 \mathrm{sec}$. in 3, 2 of whom had moderate, and 1 severe pulmonary hypertension.

Depression of the $S-T$ segment in the right pracordial leads occurred in 11 patients. It was limited to V1 in 2, but extended to V5 in 2 patients. All 11 who had S-T depression had moderate or severe pulmonary hypertension; all 4 with normal resting pulmonary artery pressure had a normal S-T segment. Five patients with moderate or severe pulmonary hypertension showed no depression of the S-T segment. All leads showing S-T depression showed an inverted T wave; the latter change, however, extended one or two leads further to the left than the leads showing the S-T depression in 9 of the 11 patients.

$T$ wave inversion in the right pracordial leads occurred in 16 patients, including 3 of the 4 patients with normal resting pulmonary pressure. In these 3 it did not extend beyond V3 and was not associated with $\mathrm{S}-\mathrm{T}$ depression. In the 13 patients with resting pulmonary hypertension and 


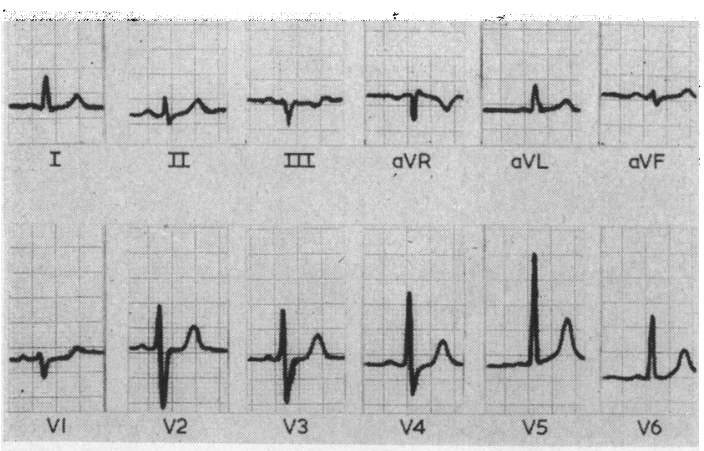

FIG. 1.-Grade 0 (absent) right ventricular hypertrophy, pulmonary artery pressure $42 / 15 \mathrm{~mm}$. $\mathrm{Hg}$, pulmonary vascular resistance 1.8 unit.

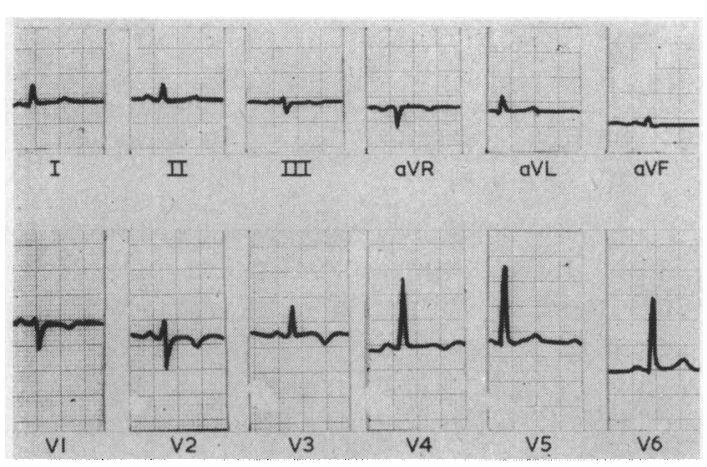

FIG. 2.-Grade 0 (absent) right ventricular hypertrophy pulmonary artery pressure $25 / 13 \mathrm{~mm}$. $\mathrm{Hg}$, pulmonary vascular resistance 1.5 unit. Note $T$ wave inversion V1 to V3.
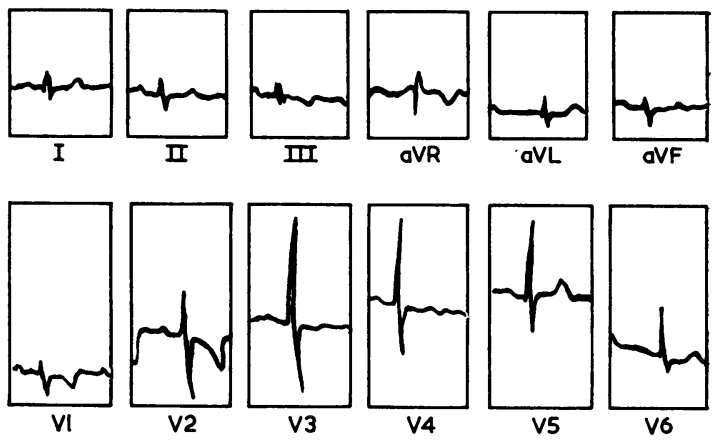

FIG. 3.-Grade 0 (absent) right ventricular hypertrophy, pulmonary artery pressure $50 / 16 \mathrm{~mm}$. Hg. Note T wave inversion in V1 to V2 (facsimile of original electrocardiogram).

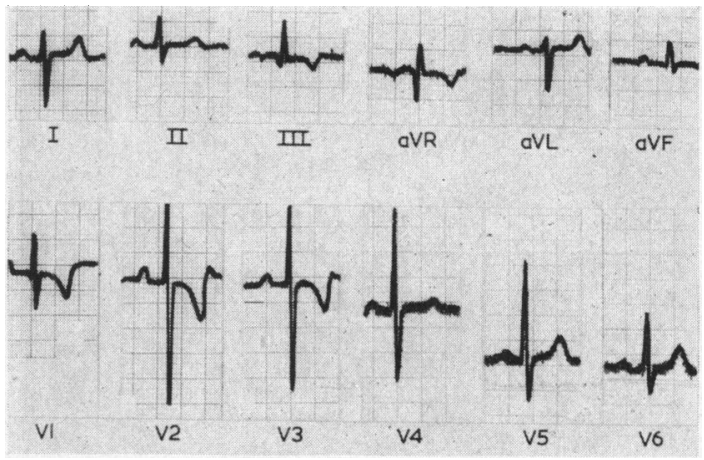

FIG. 4.-Grade 2 right ventricular hypertrophy, pulmonary artery pressure $52 / 21 \mathrm{~mm}$. Hg. Note $\mathrm{T}$ wave inversion in V1 to $\mathrm{V} 3$.

inverted $\mathrm{T}$ waves an associated $\mathrm{S}-\mathrm{T}$ depression occurred in 11 . The $\mathrm{T}$ wave inversion extended to V6 in 3 , to V5 in 1 , to V4 in 5 , to V3 in 1 , and to V2 in 3 patients.

Though $\mathrm{T}$ wave inversion extending to the left chest leads (V5 and V6) was always associated with a systolic pulmonary artery pressure over $60 \mathrm{~mm}$. $\mathrm{Hg}$ and a pulmonary vascular resistance above 6 units, yet the $\mathrm{T}$ wave changes did not closely parallel the degree of pulmonary hypertension.

Cardiographic Grades. Electrocardiographic evidence (excluding T wave inversion in V2 and V3) of right ventricular hypertrophy was lacking (grade 0) in six patients (Fig. 1, 2, and 3). The pulmonary vascular resistance was normal at rest in all and the resting pressures were normal in 3 and mildly raised in 3 . Grade 1 right ventricular hypertrophy was present in 2 patients of whom one showed normal resting pressure and pulmonary vascular resistance and the other mild pulmonary hypertension. Three patients had grade 2 (Fig. 4) and one patient had grade 3 (Fig. 5) electrocardiographic changes; all 4 had moderate or severe pulmonary hypertension. The remaining 8 patients had severe electrocardiographic changes; 3 of them had a right bundle-branch block pattern (Fig. 6) and 5 had grade 4 evidence of right ventricular hypertrophy (Fig. 7); all had moderate or severe pulmonary hypertension. They included all the patients with the highest pressures and pulmonary vascular resistances (Fig. 8). 


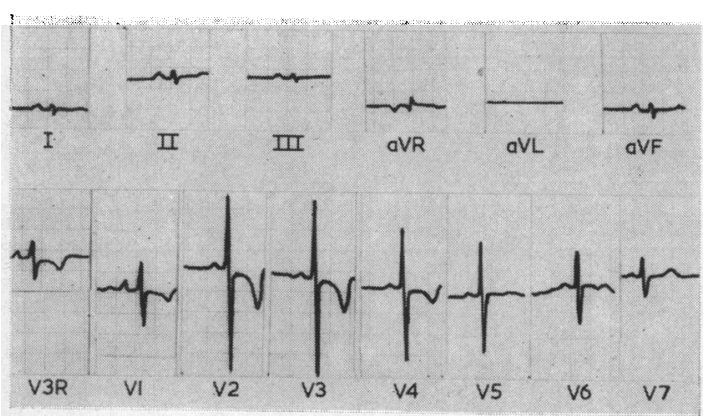

FIG. 5.-Grade 3 right ventricular hypertrophy, pulmonary artery pressure $53 / 33 \mathrm{~mm}$. $\mathrm{Hg}$, pulmonary vascular resistance $7 \cdot 1$ units. Note $T$ wave inversion V1 to V4.
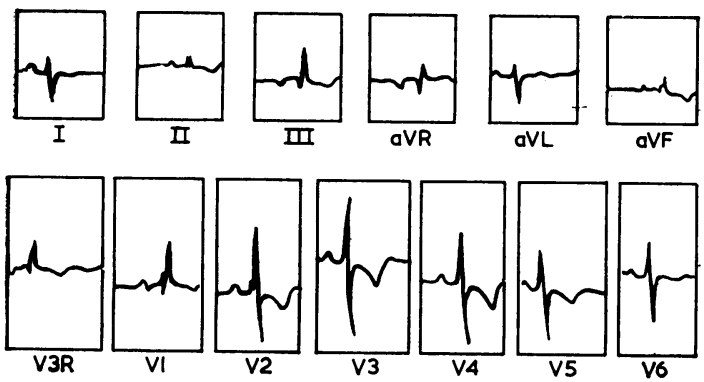

FIG. 6.-Grade 4 right ventricular hypertrophy. Partial right bundle-branch block. Pulmonary artery pressure $90 / 43 \mathrm{~mm}$. $\mathrm{Hg}$, pulmonary vascular resistance $8 \cdot 3$ units. Note $T$ wave inversion V3R to V5 (facsimile of original electrocardiogram).

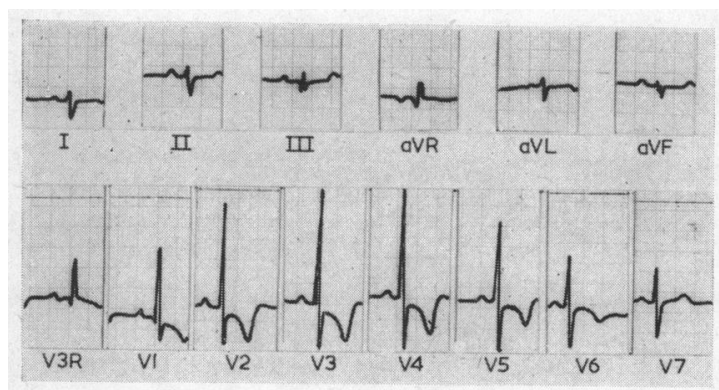

FIG. 7.-Grade 4 right ventricular hypertrophy, pulmonary artery pressure $62 / 31 \mathrm{~mm}$. $\mathrm{Hg}$, pulmonary vascular resistance 6.4 units. Note $T$ wave inversion V1 to V6. effort; severe cases show pulmonary hypertension with high vascular resistance even at rest; likewise the electrocardiogram can be normal or show evidence of all grades of right ventricular hypertrophy. Our results demonstrate that the electrocardiographic changes are related to the hæmodynamic findings. The patients with normal resting pulmonary pressures showed little if any change in the electrocardiogram; $\mathrm{T}$ inversion in leads $\mathrm{V} 1$ to $\mathrm{V} 3$ without $\mathrm{S}-\mathrm{T}$ depression was

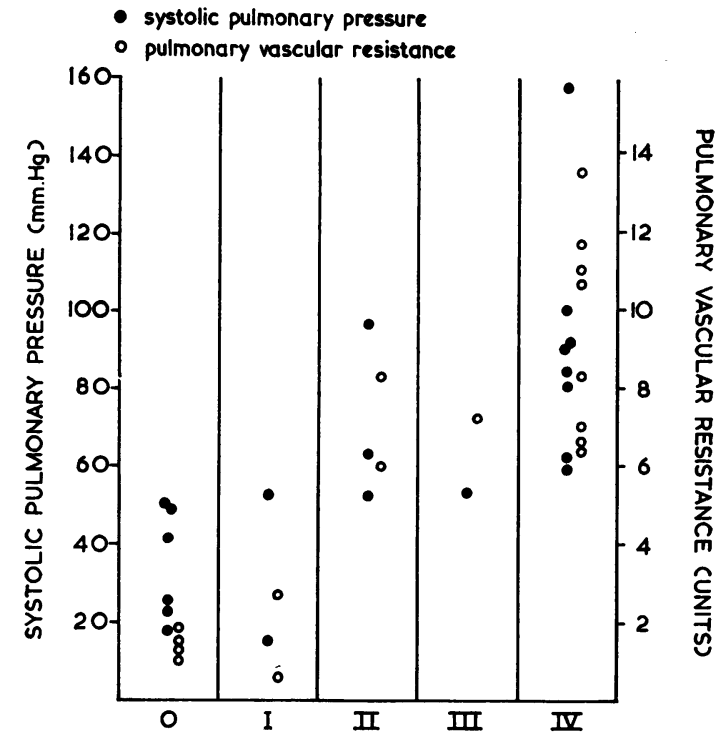

Fig. 8.-Relation between the grade of right ventricular hypertrophy, systolic pulmonary artery pressure, and pulmonary vascular resistance.

Of the 4 patients with normal resting pressures and resistances, 3 had normal electrocardiograms with mild clockwise rotation in one, in whom $\mathrm{R}$ in $\mathrm{V} 1+\mathrm{S}$ in $\mathrm{V5}$ equalled $13 \mathrm{~mm}$. The fourth patient had an R/S ratio of 1.25 in V1 as the sole electrocardiographic abnormality.

Three of them had pulmonary incompetence and electrocardiographic evidence of incomplete right bundle-branch block (rsR' pattern, QRS not exceeding $0.12 \mathrm{sec}$., with $\mathrm{S}-\mathrm{T}$ depression and $\mathrm{T}$ inversion). These were the only tracings showing this pattern.

Of the remaining 13 patients, only 2 had normal electrocardiograms; their resting pulmonary pressures and resistances were only slightly raised.

\section{Discussion}

In mild cases of bilharzial cor pulmonale, the pulmonary pressure is normal at rest and the pulmonary resistance increases only on 
TABLE IV

Relation between (RV1+SV5), Systolic Pulmonary Pressure, and Pulmonary Vascular Resistance (AVERAGE IN BRACKETS)

\begin{tabular}{|c|c|c|c|c|c|}
\hline RV1 +SV5 (mm.) & & & $1-9$ & $10-19$ & 20 and over \\
\hline $\begin{array}{l}\text { Systolic pulmonary pressure (mm. } \mathbf{H g} \text { ) } \\
\text { Pulmonary vascular resistance (units) }\end{array}$ & $\begin{array}{l}\cdots \\
\cdots\end{array}$ & $\cdots$ & $\begin{array}{c}15-42 \\
(31) \\
0 \cdot 56-1 \cdot 8 \\
(1 \cdot 23)\end{array}$ & $\begin{array}{l}17-157 \\
(69 \cdot 8) \\
1 \cdot 3-13 \cdot 5 \\
(6 \cdot 5)\end{array}$ & $\begin{array}{l}53-100 \\
(76) \\
6 \cdot 4-11 \cdot 7 \\
(8 \cdot 72)\end{array}$ \\
\hline
\end{tabular}

present in 3 , mild clockwise rotation in 1 , and an $\mathrm{R} / \mathrm{S}$ ratio of 1.25 in $\mathrm{V} 1$ in 1 patient. The electrocardiogram may remain normal if the resting pulmonary pressure is only slightly raised $(50 / 30 \mathrm{~mm}$. Hg with a mean of 36$)$. It can thus be concluded that patients with bilharzial cor pulmonale who exhibit a normal electrocardiogram or an electrocardiogram with very slight changes (grade 1) have only mild vascular changes and their resting pulmonary pressures and resistances are either normal or only slightly raised (systolic pressure below $53 \mathrm{~mm} . \mathrm{Hg}$ and pulmonary vascular resistance below 3 units). Patients with bilharzial cor pulmonale who have more pronounced electrocardiographic signs have pulmonary hypertension at rest.

Comparison of electrocardiographic signs in a single lead with the degree of pulmonary hypertension showed a wide scatter. $\mathbf{P}$ wave changes reflected atrial hypertrophy as would be expected when there is right ventricular stress and a raised right ventricular end-diastolic pressure. Since all our patients had normal end-diastolic pressures, one can presume that those who had $P$ wave changes were subjected more to periods of right ventricular stress due to augmented pulmonary resistance during exercise.

The $\mathrm{R} / \mathrm{S}$ ratio over the right præcordial leads was greater than one in nearly all the patients with resting pulmonary hypertension. Yet this ratio and also the amplitude of the $\mathbf{R}$ wave over the right chest leads did not run parallel to the degree of pulmonary hypertension. The QRS deflections are the outcome of multiple factors; the proximity of the underlying ventricle to the chest wall, the intervening tissue, and the thickness of the myocardium. It is also affected by the position of the right and left ventricles in relation to the electrode and the degree of electric potentials occurring in both. Goodwin and Abdin (1959) found that the electrocardiographic signs of right ventricular hypertrophy were affected by right ventricular systolic pressure, pulmonary vascular resistance, right ventricular dilatation, left ventricular disease, and the duration and rate of development of the disease. The absence of clear correlation between the electrocardiographic signs and the hæmodynamic data can be due to any of these factors.

In the absence of bundle-branch block a delayed intrinsicoid deflection over the right ventricle is good evidence of right ventricular hypertrophy. S-T depression and $\mathrm{T}$ wave inversion denote a strain pattern which is supposed to result from the effect of a systolic overload on repolarization (Cabrera and Monroy, 1952). The delayed intrinsicoid deflection and the S-T depression over the right præcordium were always associated with a mean resting pulmonary pressure over $35 \mathrm{~mm}$. $\mathrm{Hg}$ and a pulmonary vascular resistance above 6 units.

The $R / S$ ratio over the left præcordium was less than one in only 2 patients. The amplitude of $S$ over the left chest leads was not helpful in assessing the severity of the pulmonary hypertension because the left chest leads are far from the right ventricle and are dominated by the underlying left ventricle.

It can be seen that correlation of individual changes to the degree of pulmonary hypertension showed a wide scatter. A better correlation is obtained if all the cardiographic signs are considered (Table IV and Fig. 8). Even then, although patients with the highest pulmonary pressures and resistances had grade 4 cardiographic changes, yet the severity of the hypertension was not always reflected on the electrocardiogram. 
Right ventricular hypertrophy was reflected on the electrocardiogram by $q R$, qRs, Rs, RS, or rsR' patterns in the right præcordial leads with or without prominent $S$ waves in the left præcordial leads. A $\mathrm{Q}$ wave in the right leads is usually associated with pronounced right ventricular hypertrophy (Goodwin, 1960). It has been explained by extreme clockwise rotation producing a left ventricular pattern in the right chest leads (Kossmann et al., 1948), reversal of initial septal depolarization (Myers et al., 1948), or failure of the right præcordial leads to record an initial small $\mathrm{r}$ wave (Goodwin, 1960). The patient who had a qR pattern had the severest pulmonary hypertension; 3 other patients had qRs patterns over the right præcordial leads. These 4 patients all had grade 4 cardiographic changes of right ventricular hypertrophy.

The Rs pattern was always associated with pronounced clockwise rotation. Sodi-Pallares (1956) explains this pattern by clockwise rotation bringing the right ventricular forces closer to the chest wall. This pattern is also ascribed to hypertrophy of the free wall of the right ventricle (Goodwin, 1960).

The rs $\mathrm{R}^{\prime}$ which is frequently spoken of as incomplete right bundle-branch block pattern is a sign of right ventricular hypertrophy and need not denote a conduction defect. Cabrera and Monroy (1952) described this pattern as characteristic of a diastolic overload. El Sherif (1953) found 2 patients with incomplete right bundle-branch block among the 16 patients with bilharzial cor pulmonale he studied. He explained the pattern by defective conduction secondary to dilatation and hypertrophy. Foda (1959) reported incomplete right bundle-branch block in severe bilharzial cor pulmonale with high grades of pulmonary hypertension and vascular resistance and attributed it to a high systolic load. His tables, however, show that the pattern he described as incomplete right bundle-branch block was an $R^{\prime} R^{\prime}$ and not an rsR'. Naïm (1955) stressed the absence of an rsR' pattern in patients with bilharzial cor pulmonale. We did not meet this pattern except when pulmonary incompetence existed when all 3 patients who had pulmonary incompetence showed this electrocardiographic pattern. We believe that bilharzial cor pulmonale is characterized by a systolic overload which when reflected on the electrocardiogram produces an Rs or, when the pulmonary hypertension is very severe, a $\mathrm{qR}$ pattern in right chest leads. If pulmonary incompetence occurs a diastolic overload pattern (rsR') is produced. This pattern is attributed by Grant (1957) to right ventricular dilatation, by Walker et al. (1956) to selective hypertrophy of the basal portion secondary to increased stroke volume, by Camerini and Davies (1955) to hypertrophy of the pulmonary conus, and by Kossmann et al. (1948) to hypertrophy of the crista supraventricularis. Dilatation, increased stroke volume, and hypertrophy of the outflow tract are not expected to occur in bilharzial cor pulmonale except when pulmonary incompetence supervenes. Pulmonary incompetence occurs in bilharzial cor pulmonale when the pulmonary valves yield in front of severe hypertension and or when the pulmonary trunk is grossly dilated. Dilatation is ascribed to the augmented hypertension occurring during periods of increased physical effort (Salah, 1958). Severe pulmonary hypertension and/or increased right ventricular strain during effort would produce high grades of cardiographic hypertrophy. This was borne out in our results; all the 3 patients with pulmonary incompetence had an rsR' pattern and grade 4 changes of right ventricular hypertrophy.

It is occasionally difficult to differentiate between atrial septal defect and bilharzial cor pulmonale (Bedford et al., 1946). A diastolic overload pattern in the electrocardiogram (rsR' pattern) is taken as a sign in favour of the diagnosis of atrial septal defect. We should add that this holds true only in the absence of an early diastolic murmur in the pulmonary area.

The cardiographic appearances of bilharzial cor pulmonale are reminiscent of thromboembolic cor pulmonale rather than of hypoxic cor pulmonale. Inversion of the $\mathrm{T}$ waves in right præcordial leads, which is very frequent in thromboembolic cor pulmonale and uncommon in hypoxic cor pulmonale (Caird and Stanfield, 1929; Goodwin, Harrison, and Wilcken, 1963), occurred in 16 of our 20 patients with bilharzial cor pulmonale. Both thromboembolic cor pulmonale and bilharzial cor pulmonale have in common organic obliteration of the pulmonary vascular bed. Right atrial $\mathbf{P}$ waves, which are common in hypoxic cor pulmonale, are infrequent in bilharzial cor pulmonale.

Transient changes in the electrocardiographic signs of right ventricular hypertrophy occur during 
episodes of heart failure or increased pulmonary vascular resistance in emphysema cor pulmonale and in mitral stenosis (Goodwin et al., 1955). Similar changes occur after pulmonary embolism. Bilharzial cor pulmonale is devoid of such transient episodes of heart failure (Salah, 1958), and accordingly the electrocardiographic signs of right ventricular hypertrophy do not fluctuate.

\section{Summary AND CONClusions}

A study of the electrocardiographic signs of right ventricular hypertrophy proved useful in assessing the severity of bilharzial pulmonary hypertension. Patients with a normal electrocardiogram had normal or mildly raised resting pulmonary artery pressures, and their resting pulmonary vascular resistance was below 3 units. Patients with electrocardiographic evidence of right ventricular hypertrophy had pulmonary hypertension at rest. Signs of right ventricular hypertrophy in a single lead did not always parallel the degree of pulmonary hypertension but when all the cardiographic signs were taken together the correlation was better. The electrocardiogram in bilharzial cor pulmonale shows a "systolic overload" pattern; but if pulmonary incompetence occurs a diastolic overload pattern is superadded.

We are grateful to Prof. M. Salah, Head of the Cardiovascular Centre for his kind help and advice.

\section{REFERENCES}

Badawi, H., Effat, H., Khalil, H., Nomeir, A. M., and Salah, M. (1961). Mechanism of pulmonary hypertension in bilharzial cor pulmonale. Alexandria med.J., 7, 523.

Bedford, D. E., Aidaros, S. M., and Girgis, B. (1946). Bilharzial heart disease in Egypt; cor pulmonale due to bilharzial pulmonary endarteritis. Brit. Heart J., 8, 87.

Cabrera, E., and Monroy, J. R. (1952). Systolic and diastolic loading of the heart. I. Physiologic and clinical data. II. Electrocardiographic data. Amer. Heart J., 43, 661 and 669.

Caird, F. I., and Stanfield, C.A. (1962). The electrocardiogram in asphyxial and in embolic acute cor pulmonale. Brit. Heart J., 24, 313.

Camerini, F., and Davies, L. G. (1955). Secondary R waves in right chest leads. Brit. Heart J., 17, 28.

Cosby, R. S., Levinson, D. C., Dimitroff, S. P., Oblath, R. W., Herman, L. M., and Griffith, G. C. (1953). The electrocardiogram in congenital heart disease and mitral stenosis. Amer. Heart J., 46, 670.

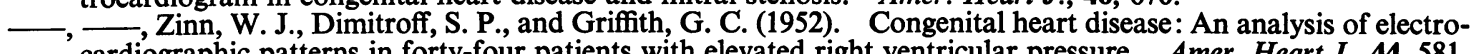
cardiographic patterns in forty-four patients with elevated right ventricular pressure. Amer. Heart J., 44, 581.

El Ramly, Z., Sorour, A., El Sherif, A., Loutfy, M., and Ibrahim, M. (1953). A clinical and hæmodynamic study of cardio-pulmonary bilharziasis. J. Egypt. med. Ass., 36, 567.

El Sherif, A. (1953). The electrocardiogram in chronic pulmonary bilharziasis. J. Egypt. med. Ass., 36, 587.

Foda, M. (1959). Hæmodynamics in bilharzial cor pulmonale. Thesis for M.D. Degree, Faculty of Med. Alexandria, U.A.R.

Goodwin, J. F. (1960). In Clinical Disorders of the Pulmonary Circulation, ed. R. Daley, J. E. Goodwin, and R. E. Steiner. Churchill, London.

- and Abdin, Z. H. (1959). The cardiogram of congenital and acquired right ventricular hypertrophy. Brit. Heart J., 21, 523.

-, Harrison, C. V., and Wilcken, D. E. L. (1963). Obliterative pulmonary hypertension and thrombo-embolism. Brit. med.J., 1,701, 777 .

—, Hunter J. D., Cleland, W. P., Davies, L. G., and Steiner, R. E. (1955). Mitral valve disease and mitral valvotomy. Brit. med.J., 2, 573.

Grant, R. P. (1957). Clinical Electrocardiography. The Spatial Vector Approach. McGraw-Hill, New York.

Kossmann, C. E., Berger, A. R., Brumlik, J., and Briller, S. A. (1948). An analysis of causes of right axis deviation based partly on endocardial potentials of the hypertrophied right ventricle. Amer. Heart J., 35, 309.

Lipman, B. S., and Massie, E. (1959). Clinical Scalar Electrocardiography, 4th ed. Year Book Publishers, Chicago.

Myers, G. B., Klein, H. A., and Stofer, B. E. (1948). The electrocardiographic diagnosis of right ventricular hypertrophy. Amer. Heart J., 35, 1.

Naim, M. M. (1955). A study of spatial vectorcardiography in bilharzial cor pulmonale. J. Egypt. med. Ass., $38,110$.

Salah, M. (1958). Chronic vascular cor pulmonale. Alexandria med. J., 4, 307.

Sal, Massoud, M. G., Badawi, H., and Effat, H. (1963). Correlation of selective pulmonary angiography and hæmodynamics in pulmonary hypertension. Proceedings of the fourth World Congress of Cardiology, Mexico City, 1962.

Sodi-Pallares, D. (1956). New Bases of Electrocardiography. Mosby, St. Louis.

Sokolow, M., and Lyon, T. P. (1949). The ventricular complex in right ventricular hypertrophy as obtained by unipolar precordial and limb leads. Amer. Heart J., 38, 273. 
Walker, I. C., Helm, R.A., and Scott, R. C. (1955). Right ventricular hypertrophy. I. Correlation of right ventricular hypertrophy at autopsy with the electrocardiographic findings. Circulation, 11, 215.

- Scott, R. C., and Helm, R. A. (1955). Right ventricular hypertrophy. II. Correlation of electrocardiographic right ventricular hypertrophy with the anatomic findings. Circulation, 11, 223.

Walker, W. J., Mattingly, T. W., Pollock, B. E., Carmichael, D. B., Inmon, T. W., and Forrester, R. H. (1956). Electrocardiographic and hemodynamic correlation in atrial septal defect. Amer. Heart J., $52,547$.

Wasserburger, R. H., and Brown, J. H. (1958). AVr-an index of right ventricular preponderance: correlation of QRS patterns in AVr and the right precordial leads with the ventricular work load ratio. Amer. Heart J., 55, 33. 